Review

\title{
Regulation of Proliferation, Differentiation and Functions of Osteoblasts by Runx2
}

\author{
Toshihisa Komori
}

Basic and Translational Research Center for Hard Tissue Disease, Nagasaki University Graduate School of Biomedical Sciences, Nagasaki 852-8588, Japan; komorit@nagasaki-u.ac.jp; Tel.: +81-95-819-7630; Fax: +81-95-819-7633

Received: 12 March 2019; Accepted: 3 April 2019; Published: 4 April 2019

\begin{abstract}
Runx2 is essential for osteoblast differentiation and chondrocyte maturation. During osteoblast differentiation, Runx2 is weakly expressed in uncommitted mesenchymal cells, and its expression is upregulated in preosteoblasts, reaches the maximal level in immature osteoblasts, and is down-regulated in mature osteoblasts. Runx2 enhances the proliferation of osteoblast progenitors by directly regulating $F g f r 2$ and $F g f r 3$. Runx2 enhances the proliferation of suture mesenchymal cells and induces their commitment into osteoblast lineage cells through the direct regulation of hedgehog (Ihh, Gli1, and Ptch1), Fgf (Fgfr2 and Fgfr3), Wnt (Tcf7, Wnt10b, and Wnt1), and Pthlh (Pthr1) signaling pathway genes, and Dlx5. Runx2 heterozygous mutation causes open fontanelle and sutures because more than half of the Runx2 gene dosage is required for the induction of these genes in suture mesenchymal cells. Runx2 regulates the proliferation of osteoblast progenitors and their differentiation into osteoblasts via reciprocal regulation with hedgehog, Fgf, Wnt, and Pthlh signaling molecules, and transcription factors, including Dlx5 and Sp7. Runx2 induces the expression of major bone matrix protein genes, including Col1a1, Spp1, Ibsp, Bglap2, and Fn1, in vitro. However, the functions of Runx2 in differentiated osteoblasts in the expression of these genes in vivo require further investigation.
\end{abstract}

Keywords: Runx2; hedgehog; Wnt; Fgfr; Pthr1; Sp7; proliferation; differentiation; cleidocranial dysplasia; osteoblast

\section{Introduction}

Runx2 belongs to the Runx family, which has the DNA-binding domain runt, and consists of Runx1, Runx2, and Runx3 [1]. Runx2 heterodimerizes with Cbfb and acquires enhanced DNA binding ability and protein stability [2-6]. Runx2 has two promoters, P1 and P2, and the transcript from P1 encodes type II Runx2 and that from P2 encodes type I Runx2. Runx2 is expressed in osteoblasts and chondrocytes. In chondrocytes, Runx 2 is weakly expressed in resting chondrocytes and upregulated in prehypertrophic chondrocytes, and this upregulated expression is maintained until terminal hypertrophic chondrocytes [7,8]. Runx2-deficient $\left(R u n \times 2^{-/-}\right)$mice lack osteoblasts and bone formation, and chondrocyte maturation is markedly inhibited [7,9-11]. Col2a1, which is

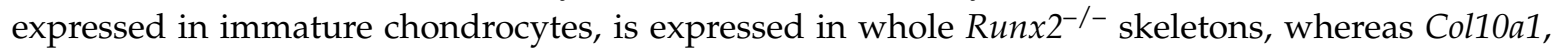
which is expressed in hypertrophic chondrocytes, is restricted to the tibia, fibula, radius, and ulna. Runx3 is also expressed in chondrocytes, and its expression is upregulated in prehypertrophic chondrocytes and down-regulated in terminal hypertrophic chondrocytes. Run $x 2^{-/-}$Run $x 3^{-/-}$mice lack hypertrophic chondrocytes, suggesting that Runx2 and Runx3 have redundant functions in chondrocyte maturation [12]. Runx2 is expressed in uncommitted mesenchymal cells, and its expression is upregulated in preosteoblasts, reaches the maximum level in immature osteoblasts, and is down-regulated in mature osteoblasts $[13,14]$. Furthermore, Runx2 regulates the proliferation of 
osteoblast progenitors, their commitment to osteoblast lineage cells, and the expression of bone matrix protein genes.

\section{Reciprocal Regulation of the Essential Transcription Factors for Osteoblast Differentiation}

Hedgehog signaling is essential for osteoblast differentiation in endochondral bone. Hedgehog binding to Ptch relieves the repression of Smo, which ultimately regulates Gli [15]. Osteoblasts are absent in $I h h^{-/-}$endochondral skeletons and Runx2 expression is absent in the perichondrium [16]. Ihh conditional knockout mice created by crossing with Col2a1 promoter Cre transgenic mice in which Cre is expressed in chondrocytes and perichondrial cells, which are progenitors of osteoblasts, do not form bone. Further, osteoblast marker gene expression, including Runx2, is absent from the perichondrium [17]. In Smo conditional knockout mice created by crossing with Col2a1 Cre transgenic mice, Runx 2 expression is only induced outside of the perichondrium where osteoblast progenitors are located, and primary spongiosa is not formed, suggesting that hedgehog signaling is required for Run $x 2$ expression in the perichondrium and Runx2-expressing perichondrial cells are required for primary spongiosa formation [18] (Figure 1). However, the requirement of hedgehog signaling in osteoblast differentiation is transient because the deletion of Smo using $S p 7$ promoter Cre transgenic mice in which Cre expression begins at the preosteoblast stage does not affect osteoblast differentiation [19]. The sources of osteoblasts in primary spongiosa have been demonstrated to be Sp7-expressing perichondrial cells and the transdifferentiated osteoblasts from hypertrophic chondrocytes [20-22]. Runx2 directly regulates thh expression in chondrocytes, osteoblast progenitors, and osteoblasts, as well as Gli1 and Ptch1 expression in osteoblast progenitors and osteoblasts [12,14]. Thus, Runx2 and hedgehog signaling regulate each other, and induce osteoblast differentiation (Figure 1).

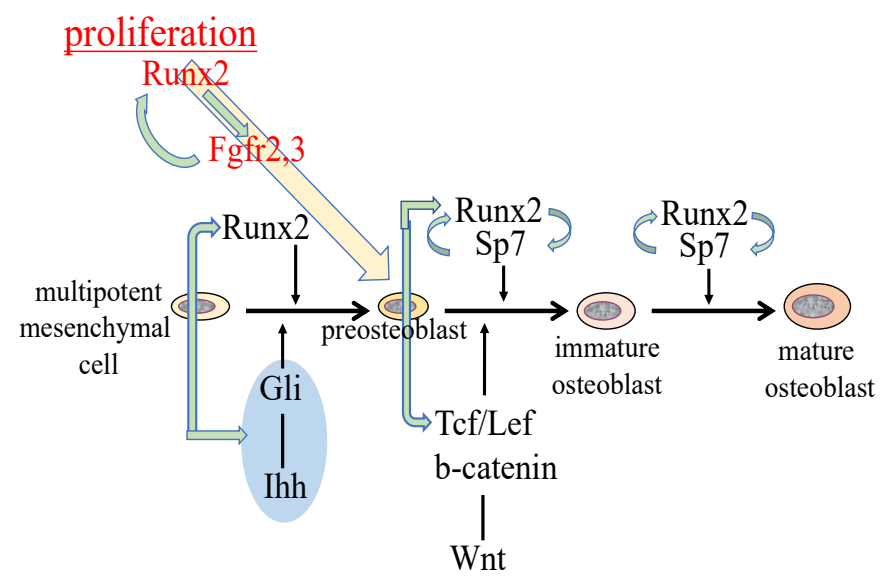

Figure 1. Regulation of osteoblast proliferation and differentiation by transcription factors. Runx2 induces the differentiation of multipotent mesenchymal cells into preosteoblasts. Ihh is required for the expression of Runx2 in the perichondrium of endochondral bones. Runx2 induces Sp7 expression, and Runx2, Sp7, and canonical Wnt signaling induce the differentiation of preosteoblasts into immature osteoblasts. Runx2 and Sp7 are also involved in the maturation of osteoblasts. Runx2 regulates the proliferation of preosteoblasts by inducing Fgfr2 and Fgfr3. Runx2 expression and that of hedgehog, Fgf, and Wnt signaling pathway genes, and $S p 7$ are reciprocally regulated.

Runx2 directly regulates $S p 7$ expression, and osteoblasts and bone formation are also absent in $S p 7^{-/-}$mice [23,24]. As Runx2 is an upstream transcription factor of Sp7, Runx2 is expressed in $S p 7^{-/-}$mice [24,25]. One major difference between $R u n x 2^{-/-}$mice and $S p 7^{-/-}$mice is the number of mesenchymal cells in the presumptive bone regions. There are abundant mesenchymal cells that express Runx 2 in the presumptive bone regions in $S p 7^{-/-}$mice, whereas there are few in these regions in Runx $2^{-/-}$mice [25]. This suggests that Runx2 is required for the expansion of mesenchymal cells, as described in detail later. As Sp7 activates an osteoblast-specific enhancer of Runx2, Sp7 is also 
involved in the regulation of Runx2 expression [26] (Figure 1). Canonical Wnt signaling is also essential for osteoblast differentiation. In conditional Ctnnb1 knockout mice created by crossing with Twist2 (Dermo1) Cre knock-in mice in which Ctnnb1 is deleted in osteo-chondroprogenitors, osteoblasts are absent, Runx2 is expressed in the perichondrial cells, and $S p 7$ expression is weak or absent in perichondrial cells $[27,28]$. Conditional Ctnnb1 knockout mice created by crossing with Col2a1 promoter Cre transgenic mice or Prrx1 promoter Cre transgenic mice in which Ctnnb1 is deleted in osteoblast progenitors in calvaria and osteo-chondroprogenitors in limb skeletons also lack osteoblasts in the Cre-expressing skeletons $[19,29]$. Similar to $S p 7^{-/-}$mice, conditional $C t n n b 1^{-/-}$mice also have abundant mesenchymal cells that express Runx2 in the presumptive bone region, suggesting again that Runx2 is required for the expansion of mesenchymal cells. As some of the mesenchymal cells in the perichondrium and calvaria differentiate into chondrocytes in $S p 7^{-/-}$mice and conditional Ctnnb1 $1^{-/-}$mice, Sp7 and canonical Wnt signaling inhibit chondrocyte differentiation and direct Runx $2^{+}$ osteoblast progenitors to become osteoblasts (Figure 1).

\section{Regulation of the Proliferation of Osteoblast Progenitors by Runx2}

Overexpression of Runx 2 under the control of the Prrx 1 promoter accelerated osteoblast differentiation, inhibited chondrocyte differentiation, and caused limb defects [30]. The epithelialmesenchymal interaction loop formed by Fgfs and Fgfrs is essential for limb development. The epithelial-mesenchymal interaction is formed by the different affinities of Fgfs for Fgfr1-3 with the alternatively spliced Ig-like domains of IIIb ("b") and IIIc ("c") [31]. Fgf10, which is expressed in the mesenchyme of the limbs, has a high affinity for Fgfr2b in the apical ectodermal ridge (AER), and induces Fgf4 and Fgf8 in the AER. Fgf4 and Fgf8 have a high affinity for Fgfr1c and Fgfr2c, which are expressed in the mesenchyme, and induce the proliferation of the mesenchymal cells. The limb defects in Runx2 transgenic mice were caused by the induction of IIIb isoforms of Fgfr1 and Fgfr2, which have a high affinity for Fgf10, in the mesenchyme, leading to failure of the AER formation and Fgf4 and Fgf8 induction in that region. Consistent with Fgfr1-3 induction in Runx2 transgenic mice, overexpression or knockdown experiments, and reporter and ChIP assays demonstrated that Runx2 directly regulates $F g f r 1, F g f r 2$, and $F g f r 3$ [25].

Among Fgfr1-3, the expression levels were $F g f r 1>F g f r 2>F g f r 3$ in calvarial tissues. Fgfr2 and Fgfr3 play roles in the proliferation of osteoblast progenitors, and they induce proliferation through the mitogen-activated protein kinases (MAPK) signaling pathway. The expression of $F \& f r 1-3$ was markedly reduced in Runx $2^{-/-}$calvaria but not in $S p 7^{-/-}$calvaria. Runx2 increased the proliferation of wild-type osteoblast progenitors and augmented Fgf2-induced proliferation. However, Wnt3a, Ihh, Shh, and PTHrP (1-34) failed to increase the proliferation or augment Runx2-induced proliferation. Thus, Fgf signaling plays a major role in the proliferation of osteoblast progenitors, and Runx 2 regulates the proliferation of osteoblast progenitors by inducing Fgfr2 and Fgfr3 [25] (Figure 1).

However, in all of the previous reports, Runx2 negatively regulated the proliferation of osteoblast lineage cells. Run $x 2^{-/-}$calvarial cells proliferated faster than wild-type calvarial cells in vitro [32]. Runx2 expression was up-regulated in the G0 phase and down-regulated in the G1 phase of the cell cycle of MC3T3-E1 preosteoblastic cells [33]. Furthermore, Runx2 suppressed the proliferation of cells with osteogenic potential and osteosarcoma cells, and the introduction of siRNA against Run $x 2$ into human mesenchymal stem cells increased their proliferation [34,35]. Moreover, Runx2 induced G1 cell-cycle arrest through the induction of $C d k n 1 b\left(\mathrm{p} 27^{\mathrm{KIP} 1}\right.$ ) in osteosarcoma cells, the expression of

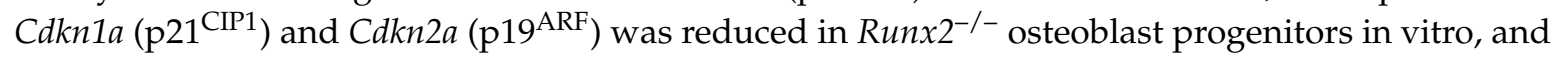
the introduction of Runx2 induced the expression of $C d k n 1 b, C d k n 1 a$, and $C d k n 2 a$, suggesting that they are targeting genes responsible for the inhibitory function of Runx 2 in the proliferation of osteoblast lineage cells [36,37]. In the previous report, marked reduction of $C d k n 1 a$ and $C d k n 2 a$ expression in Run $x 2^{-/-}$calvarial cells occurred after six passages of the cells [37]. In our analysis using Run $x 2^{-/-}$ calvarial cells after one passage, $C d k n 1 b$ expression in Run $x 2^{-/-}$calvarial cells was greater than that in wild-type calvarial cells, Cdkn1a, Cdkn2a (p19ARF), and Cdkn2a (p16 $\left.{ }^{\text {Ink4a }}\right)$ expression in Runx $2^{-/-}$ 
calvarial cells was approximately $75 \%$ of that in wild-type calvarial cells, and the introduction of Run $x 2$ failed to induce the expression of these genes [25]. Moreover, the expression profiles of Runx $2^{-/-}$ calvarial cells compared with wild-type calvarial cells differed between in vitro and in vivo samples, thereby explaining the discrepancies between the in vitro and in vivo findings [25].

It is difficult to investigate the proliferation of osteoblast lineage cells in vivo because osteoblast lineage cells at different stages of differentiation are mixed and the differentiation stage affects their proliferation. Both Run $x 2^{-/-}$mice and $S p 7^{-/-}$mice have cartilaginous skeletons, and lack osteoblasts and bone formation $[9,10,24] . S p 7^{-/-}$mice have abundant mesenchymal cells, which express Col1a1 weakly and are actively proliferating, in the presumptive bone regions, whereas Run $\times 2^{-/-}$mice have few mesenchymal cells, which express Col1a1 at a markedly low level and have low proliferative activity, in the presumptive bone regions [25]. Furthermore, Runx2, Fgfr2, and Fgfr3 are expressed in the mesenchymal cells in $S p 7^{-/-}$mice at levels comparable to those in osteoblasts in wild-type mice. These suggest that mesenchymal cells in $S p 7^{-/-}$mice are preosteoblasts and that $S p 7^{-/-}$mice are an appropriate model for the investigation of preosteoblast proliferation because osteoblast differentiation is blocked at the preosteoblast stage. $\mathrm{Sp}^{-/-}$preosteoblasts proliferated at a similar level as wild-type osteoblast lineage cells in vivo, but they proliferated faster than wild-type osteoblast progenitors in vitro. Fgf2 augmented the proliferation of $S p 7^{-/-}$preosteoblasts, whereas knockdown of Runx2 inhibited this augmentation and reduced the expression of $F g f r 2$ and Fgfr3. The amount and proliferation of preosteoblasts in $S p 7^{-/-}$mice was halved in $S p 7^{-/-}$Run $x 2^{+/-}$mice, indicating that preosteoblast proliferation is dependent on the gene dosage of Run $x 2$. Therefore, Runx 2 is required for preosteoblast proliferation in vivo, and Runx2 regulates it through the induction of Fgfr 2 and Fgfr3 [25]. Moreover, Fgf2 enhances the Runx2 capacity for transcriptional activation via the PKC and MAPK pathways [25,38-41]. Thus, the Fgf signaling pathway and Runx2 positively regulate each other (Figure 1).

\section{Molecular Mechanism of the Pathogenesis of Open Fontanelles and Sutures in Cleidocranial Dysplasia (CCD)}

Although both intramembranous and endochondral bone development are affected in cleidocranial dysplasia (CCD), the open fontanelles and sutures and hypoplastic clavicles are typical features of CCD $[5,42,43]$. However, why the development of calvaria and clavicles is the most severely affected in CCD remains unclear. The posterior frontal (PF) suture is unique among the processes of suture closure. Mesenchymal condensation occurs at the PF suture at around P7 in mice, when osteogenic fronts closely face each other, and the mesenchymal cells differentiate into chondrocytes. Chondrocytes mature, cartilage is replaced with bone through endochondral ossification, each side of the frontal bone completely fuses, and the PF suture completely closes radiologically and histologically [44,45]. The differentiation of suture mesenchymal cells into chondrocytes is likely caused, at least in part, by the reduction of Wnt signaling, which inhibits chondrocyte differentiation, in the PF suture when the osteogenic fronts face each other [14,46]. The process of endochondral ossification is not observed in the other sutures, including the sagittal (SAG) suture, and the sutures close radiologically, but both sides of calvarial bones do not fuse histologically.

In Run $x 2^{+/-}$mice, the closure of both PF and SAG sutures was interrupted, and cartilaginous tissue was not observed in the PF suture. The suture mesenchymal cells expressed Sox 9 at a similar level in wild-type and Run $x 2^{+/-}$mice. The suture mesenchymal cells also expressed Runx2, but the expression level in $R u n x 2^{+/-}$mice was half of that in wild-type mice. The cell density and cell proliferation in Run $x 2^{+/-}$sutures was less than those in wild-type mice. The expression of hedgehog signaling genes (Gli1, Ptch1, and Ihh), Fgf signaling genes (Fgfr2 and Fgfr3), Wnt signaling genes

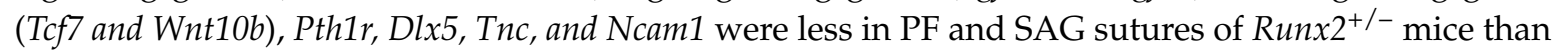
in those of wild-type mice. Overexpression or knockdown of Runx2 and ChIP analysis demonstrated that these genes are directly regulated by Runx2 (Figure 2). However, the expression levels of these genes, except Dlx5, were similar in calvarial bone tissues between wild-type and Runx $2^{+/-}$mice. 
Furthermore, osteoblast marker gene expression was not reduced in the calvarial bone tissues of Run $x 2^{+/-}$mice. These findings indicate that more than half of the Run $x 2$ gene dosage is required for the expression of these Runx 2 target genes in suture mesenchymal cells, but half of the Runx 2 gene dosage is sufficient for it in differentiated osteoblasts [14].

In organ culture of Run $x 2^{+/-}$calvaria, the ligands or agonists for hedgehog, Fgf, Wnt, and Pthlh signaling pathways enhanced calvarial bone development and suture closure. Furthermore, the antagonists of hedgehog, Fgf, Wnt, and Pthlh signaling pathways inhibited calvarial bone development, suture closure, and proliferation of suture mesenchymal cells in the organ culture of wild-type calvaria. These findings suggested that hedgehog, Fgf, Wnt, and Pthlh signaling pathways are involved in the expansion, condensation, and commitment of suture mesenchymal cells to osteoblast lineage cells, and that Runx2 regulates these processes by inducing their signaling pathway genes [14] (Figure 2).

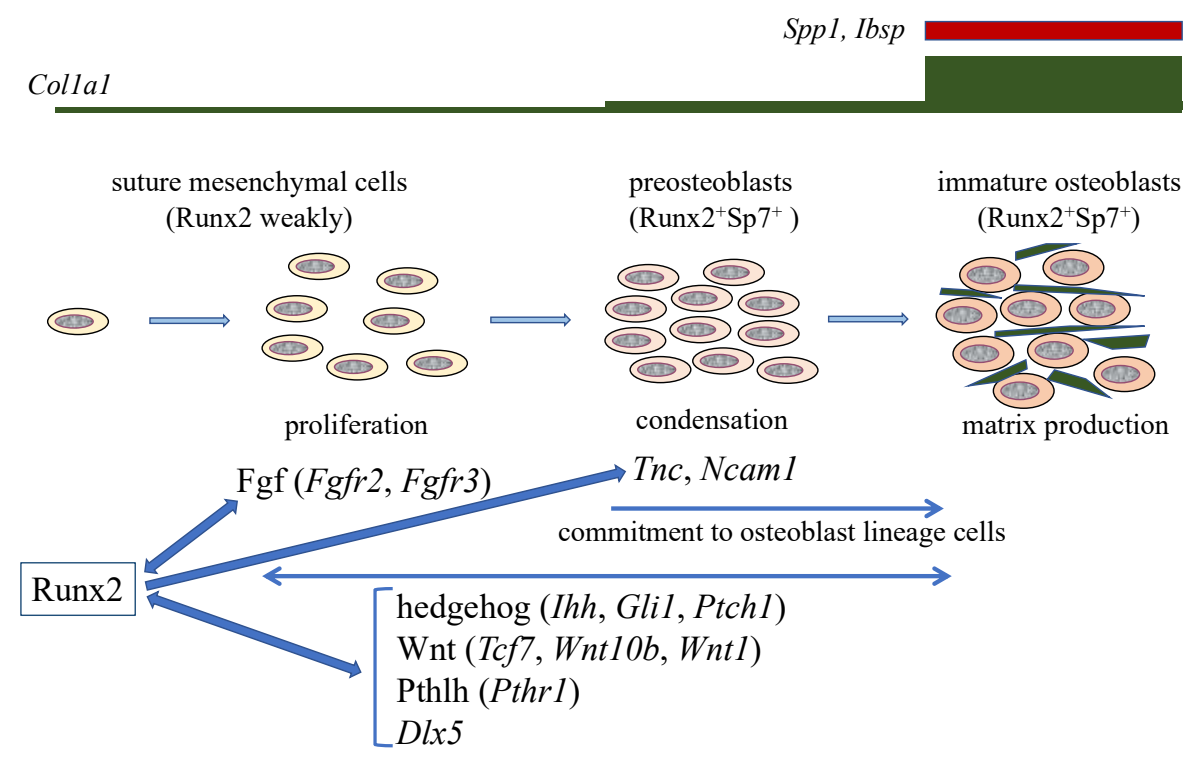

Figure 2. Calvarial bone development and suture closure. Suture mesenchymal cells weakly express Run $x$, and its expression is upregulated in preosteoblasts and reaches the maximum level in immature osteoblasts. Runx 2 induces $S p 7$ expression at the preosteoblast stage. Col1a1 expression is weak in suture mesenchymal cells, slightly upregulated in preosteoblasts, and markedly upregulated in immature osteoblasts, which also express Spp1 and Ibsp. Runx2 increases the proliferation of suture mesenchymal cells and induces their commitment into osteoblast lineage cells through the induction of Fgf (Fgfr2 and Fgfr3), hedgehog (Ihh, Gli1, and Ptch1), Wnt (Tcf7, Wnt10b, and Wnt1), and Pthlh (Pthr1) signaling pathway genes, and Dlx5. Fgf signaling plays a role in proliferation, whereas the other genes function in both proliferation and commitment. There is reciprocal regulation between Runx2, and these signaling pathways and Dlx5. In the processes of commitment into osteoblast lineage cells, Runx2 also induces Tnc and Ncam1, which likely play roles in the condensation of suture mesenchymal cells, and these condensed mesenchymal cells then become preosteoblasts. The preosteoblasts become immature osteoblasts in the sagittal (SAG) suture, but not in the posterior frontal (PF) suture, where they become chondrocytes due, at least in part, to the reduction of Wnt signaling.

Runx2 directly regulates the expression of Tcf7, Wnt10b, and Wnt1, and Tcf7 and Ctnnb1 activate the P1 promoter and osteoblast-specific enhancer of Runx2 [14,26,47,48]. Thus, Wnt signaling and Runx2 mutually regulate their expression (Figures 1 and 2). As Dlx5 activates the P1 promoter and osteoblast-specific enhancer of Runx2 [26,49], Dlx5 and Runx2 also mutually regulate their expression (Figure 2). In addition, parathyroid hormone (PTH) increases Run $x 2$ mRNA, Runx2 protein, and Runx2 activity, PTH induces Mmp13 promoter activity by activating Runx2 through PKA, and intermittent administration of PTH exerts lower anabolic effects on osteoblast-specific dominant-negative Runx 2 or 
overexpressing Runx2 transgenic mice [13,50-52]. PTH and Pthlh share a common signaling pathway; therefore, there is also reciprocal regulation between the Pthlh signaling pathway and Runx2 (Figure 2).

\section{The Functions of Runx2 in Bone Matrix Protein Gene Expression}

After commitment to osteoblastic lineage cells, the osteoblasts express bone matrix protein genes at different levels depending on the maturational stage of the cells. Uncommitted mesenchymal cells weakly express Col1a1, its expression is slightly upregulated in preosteoblasts, and is markedly upregulated in immature osteoblasts [14] (Figure 2). Immature osteoblasts express Spp1 and then Ibsp, and mature osteoblasts strongly express Col1a1 and Bglap2 [13,53] (Figure 2). Mature osteoblasts are embedded into the bone matrix and become immature osteocytes, which express Dmp1, and become mature osteocytes, which express Sost [54-56].

Run $x 2^{-/-}$mice lack osteoblasts, and the expression of bone matrix protein genes, including Spp1, Ibsp, and Bglap2, is absent and Col1a1 expression is very low in the presumptive bone regions [7,9]. Although osteoblasts are observed in type II Runx2-specific knockout mice, the expression of Col1a1, Spp1, and Bglap2 is reduced [57]. In vitro studies also demonstrated that Runx2 is a positive regulator that can upregulate the expression of bone matrix protein genes, including Col1a1, Spp1, Ibsp, Bglap2, and $F n 1$ [58-61]. Moreover, reporter assays revealed that Runx2 activates the promoters of bone matrix protein genes, including Col1a1, Col1a2, Spp1, and Bglap2 [59,60,62-64].

The most important function of osteoblasts is the production of type I collagen, which composes $90 \%$ of bone. Type I collagen is a heterotrimeric protein comprising two $\alpha 1$ (I) chains and one $\alpha 2(\mathrm{I})$ chain, which are encoded by Col1a1 and Col1a2, respectively. Reporter mice demonstrated that a 0.9-kb Col1a1 promoter directs weak reporter gene expression in skin fibroblasts, a 2.3-kb Col1a1 promoter directs additional strong reporter gene expression in osteoblasts and odontoblasts, and a 3.2-kb Col1a1 promoter directs additional strong reporter gene expression in tendon and fascia fibroblasts [65]. Reporter mice covering the Col1a2 gene locus clarified the presence of an enhancer in the region between -13.5 and $-19.5 \mathrm{~kb}$ of the Col1a2 gene [66].

In a reporter assay, a Runx 2 binding motif, which is conserved in mice, rats, and humans, located at -1347 in the mouse Col1a1 gene was found to be responsible for transcriptional activation by Runx2 [63]. However, deletion of the comparable region in rats had no effect [67]. Conditional deletion of the runt domain of Runx2, which is required for DNA binding, in osteoblasts using 2.3-kb Col1a1 promoter Cre transgenic mice resulted in similar bone volume and bone formation as in wild-type mice [68]. In contrast, conditional deletion of exon 8 of Runx 2 using the same 2.3-kb Col1a1 promoter Cre transgenic mouse line resulted in the expression of cryptic Runx2 protein, which has a lower capacity for transcriptional activation, leading to reduced bone mass [69]. Although the expression of Col1a1 and Col1a2 was not examined in either report, their expression is likely unaffected in the former and reduced in the latter. In the latter case, however, the cryptic Runx2 protein retains the capacity for nuclear import and DNA binding. Therefore, the cryptic Runx 2 protein may reduce bone mass by inhibiting the binding of Runx3, because the deletion of Runx3 in osteoblasts using the 2.3-kb Col1a1 promoter Cre transgenic mice results in osteopenia [70]. Although Col1a1 expression has been reported to precede Runx2 expression [71], Col1a1 expression in uncommitted mesenchymal cells of Run $x 2^{-/-}$ mice and preosteoblasts of $S p 7^{-/-}$mice is very weak, and Colla1 expression is greatly upregulated after commitment into osteoblasts in wild-type mice [14] (Figure 2). Therefore, the involvement of Runx2 in Col1a1 expression in differentiated osteoblasts in vivo requires further investigation.

$\mathrm{Sp} 7$ is involved in Col1a1 expression in vitro, and Runx2 and Sp7 cooperatively regulate Col1a1 expression, which is augmented through phosphorylation by p38 and ERK [72-74]. The bone mass was reduced in vertebrae, trabecular bone was increased and cortical bone was reduced in femurs, and Col1a1 expression was unchanged in $S p 7^{\mathrm{fl} /-} ; 2.3-\mathrm{kb}$ Col1a1 Cre mice [75]. In $S p 7^{\mathrm{fl} /-} ; 2.3-\mathrm{kb}$ Col1a1 CreERT2 mice, the induction of Cre activity by 4-hydroxytamoxifen reduced bone mass in vertebrae and Col1a1 expression in long bones [76]. Although the results are inconsistent, Sp7 may play a role in Col1a1 expression in differentiated osteoblasts in vivo. 


\section{Conclusions}

Runx2 is required for the proliferation of preosteoblasts in whole skeletons and mesenchymal cells in sutures. Indeed, Runx 2 is required for the commitment of mesenchymal cells to osteoblast lineage cells. Thus, Runx 2 makes a condensed cell layer of uncommitted mesenchymal cells or osteoblast progenitors by increasing their proliferation and facilitates their differentiation into osteoblast lineage cells. Runx2 can exert multiple functions through reciprocal regulation via major signaling pathways, including Fgf, hedgehog, Wnt, and Pthlh, and transcription factors, including Sp7 and Dlx5. Osteoblast proliferation and differentiation are likely regulated by such reciprocal regulation rather than the cascade of transcription factors.

Funding: This work was supported by grants from the Japanese Ministry of Education, Culture, Sports, Science and Technology (Grant number: 18H05283).

Conflicts of Interest: The authors declare no conflict of interest.

\section{References}

1. Komori, T. Roles of Runx2 in Skeletal Development. Adv. Exp. Med. Biol. 2017, 962, 83-93. [PubMed]

2. Kundu, M.; Javed, A.; Jeon, J.P.; Horner, A.; Shum, L.; Eckhaus, M.; Muenke, M.; Lian, J.B.; Yang, Y.; Nuckolls, G.H.; et al. Cbfbeta interacts with Runx2 and has a critical role in bone development. Nat. Genet. 2002, 32, 639-644. [CrossRef]

3. Miller, J.; Horner, A.; Stacy, T.; Lowrey, C.; Lian, J.B.; Stein, G.; Nuckolls, G.H.; Speck, N.A. The core-binding factor beta subunit is required for bone formation and hematopoietic maturation. Nat. Genet. 2002, 32, 645-649. [CrossRef] [PubMed]

4. Yoshida, C.A.; Furuichi, T.; Fujita, T.; Fukuyama, R.; Kanatani, N.; Kobayashi, S.; Satake, M.; Takada, K.; Komori, T. Core-binding factor beta interacts with Runx2 and is required for skeletal development. Nat. Genet. 2002, 32, 633. [CrossRef] [PubMed]

5. Qin, X.; Jiang, Q.; Matsuo, Y.; Kawane, T.; Komori, H.; Moriishi, T.; Taniuchi, I.; Ito, K.; Kawai, Y.; Rokutanda, S.; et al. Cbfb regulates bone development by stabilizing Runx family proteins. J. Bone Miner. Res. 2015, 30, 706-714. [CrossRef]

6. Lim, K.E.; Park, N.R.; Che, X.; Han, M.S.; Jeong, J.H.; Kim, S.Y.; Park, C.Y.; Akiyama, H.; Kim, J.E.; Ryoo, H.M.; et al. Core binding factor beta of osteoblasts maintains cortical bone mass via stabilization of Runx2 in mice. J. Bone Miner. Res. 2015, 30, 715-722. [CrossRef] [PubMed]

7. Inada, M.; Yasui, T.; Nomura, S.; Miyake, S.; Deguchi, K.; Himeno, M.; Sato, M.; Yamagiwa, H.; Kimura, T.; Yasui, N.; et al. Maturational disturbance of chondrocytes in Cbfa1-deficient mice. Dev. Dyn. 1999, 214, 279-290. [CrossRef]

8. Enomoto, H.; Enomoto-Iwamoto, M.; Iwamoto, M.; Nomura, S.; Himeno, M.; Kitamura, Y.; Kishimoto, T.; Komori, T. Cbfa1 is a positive regulatory factor in chondrocyte maturation. J. Biol. Chem. 2000, 275, 8695-8702. [CrossRef] [PubMed]

9. Komori, T.; Yagi, H.; Nomura, S.; Yamaguchi, A.; Sasaki, K.; Deguchi, K.; Shimizu, Y.; Bronson, R.T.; Gao, Y.H.; Inada, M.; et al. Targeted disruption of Cbfa1 results in a complete lack of bone formation owing to maturational arrest of osteoblasts. Cell 1997, 89, 755-764. [CrossRef]

10. Otto, F.; Thornell, A.P.; Crompton, T.; Denzel, A.; Gilmour, K.C.; Rosewell, I.R.; Stamp, G.W.; Beddington, R.S.; Mundlos, S.; Olsen, B.R.; et al. Cbfa1, a candidate gene for cleidocranial dysplasia syndrome, is essential for osteoblast differentiation and bone development. Cell 1997, 89, 765-771. [CrossRef]

11. Kim, I.S.; Otto, F.; Zabel, B.; Mundlos, S. Regulation of chondrocyte differentiation by Cbfa1. Mech. Dev. 1999, 80, 159-170. [CrossRef]

12. Yoshida, C.A.; Yamamoto, H.; Fujita, T.; Furuichi, T.; Ito, K.; Inoue, K.; Yamana, K.; Zanma, A.; Takada, K.; Ito, Y.; et al. Runx2 and Runx3 are essential for chondrocyte maturation, and Runx2 regulates limb growth through induction of Indian hedgehog. Genes Dev. 2004, 18, 952-963. [CrossRef]

13. Maruyama, Z.; Yoshida, C.A.; Furuichi, T.; Amizuka, N.; Ito, M.; Fukuyama, R.; Miyazaki, T.; Kitaura, H.; Nakamura, K.; Fujita, T.; et al. Runx2 determines bone maturity and turnover rate in postnatal bone development and is involved in bone loss in estrogen deficiency. Dev. Dyn. 2007, 236, 1876-1890. [CrossRef] 
14. Qin, X.; Jiang, Q.; Miyazaki, T.; Komori, T. Runx2 regulates cranial suture closure by inducing hedgehog, Fgf, Wnt, and Pthlh signaling pathway gene expression in suture mesenchymal cells. Hum. Mol. Genet. 2018, 28, 896-911. [CrossRef]

15. Simpson, F.; Kerr, M.C.; Wicking, C. Trafficking, development and hedgehog. Mech. Dev. 2009, 126, $279-288$. [CrossRef] [PubMed]

16. St-Jacques, B.; Hammerschmidt, M.; McMahon, A.P. Indian hedgehog signaling regulates proliferation and differentiation of chondrocytes and is essential for bone formation. Genes Dev. 1999, 13, 2072-2086. [CrossRef]

17. Razzaque, M.S.; Soegiarto, D.W.; Chang, D.; Long, F.; Lanske, B. Conditional deletion of Indian hedgehog from collagen type 2alpha1-expressing cells results in abnormal endochondral bone formation. J. Pathol. 2005, 207, 453-461. [CrossRef] [PubMed]

18. Long, F.; Chung, U.I.; Ohba, S.; McMahon, J.; Kronenberg, H.M.; McMahon, A.P. Ihh signaling is directly required for the osteoblast lineage in the endochondral skeleton. Development 2004, 131, 1309-1318. [CrossRef] [PubMed]

19. Rodda, S.J.; McMahon, A.P. Distinct roles for Hedgehog and canonical Wnt signaling in specification, differentiation and maintenance of osteoblast progenitors. Development (Cambridge, England) 2006, 133, 3231-3244. [CrossRef] [PubMed]

20. Yang, L.; Tsang, K.Y.; Tang, H.C.; Chan, D.; Cheah, K.S. Hypertrophic chondrocytes can become osteoblasts and osteocytes in endochondral bone formation. Proc. Natl. Acad. Sci. USA 2014, 111, 12097-12102. [CrossRef]

21. Zhou, X.; von der Mark, K.; Henry, S.; Norton, W.; Adams, H.; de Crombrugghe, B. Chondrocytes transdifferentiate into osteoblasts in endochondral bone during development, postnatal growth and fracture healing in mice. PLoS Genet. 2014, 10, e1004820. [CrossRef]

22. Maes, C.; Kobayashi, T.; Selig, M.K.; Torrekens, S.; Roth, S.I.; Mackem, S.; Carmeliet, G.; Kronenberg, H.M. Osteoblast precursors, but not mature osteoblasts, move into developing and fractured bones along with invading blood vessels. Dev. Cell 2010, 19, 329-344. [CrossRef]

23. Yoshida, C.A.; Komori, H.; Maruyama, Z.; Miyazaki, T.; Kawasaki, K.; Furuichi, T.; Fukuyama, R.; Mori, M.; Yamana, K.; Nakamura, K.; et al. SP7 Inhibits Osteoblast Differentiation at a Late Stage in Mice. PLoS ONE 2012, 7, e32364. [CrossRef]

24. Nakashima, K.; Zhou, X.; Kunkel, G.; Zhang, Z.; Deng, J.M.; Behringer, R.R.; de Crombrugghe, B. The novel zinc finger-containing transcription factor osterix is required for osteoblast differentiation and bone formation. Cell 2002, 108, 17-29. [CrossRef]

25. Kawane, T.; Qin, X.; Jiang, Q.; Miyazaki, T.; Komori, H.; Yoshida, C.A.; Matsuura-Kawata, V.; Sakane, C.; Matsuo, Y.; Nagai, K.; et al. Runx2 is required for the proliferation of osteoblast progenitors and induces proliferation by regulating Fgfr2 and Fgfr3. Sci. Rep. 2018, 8, 13551. [CrossRef] [PubMed]

26. Kawane, T.; Komori, H.; Liu, W.; Moriishi, T.; Miyazaki, T.; Mori, M.; Matsuo, Y.; Takada, Y.; Izumi, S.; Jiang, Q.; et al. Dlx5 and Mef2 regulate a novel Runx2 enhancer for osteoblast-specific expression. J. Bone Miner. Res. 2014, 29, 1960-1969. [CrossRef] [PubMed]

27. Day, T.F.; Guo, X.; Garrett-Beal, L.; Yang, Y. Wnt/beta-catenin signaling in mesenchymal progenitors controls osteoblast and chondrocyte differentiation during vertebrate skeletogenesis. Dev. Cell 2005, 8, 739-750. [CrossRef]

28. Hu, H.; Hilton, M.J.; Tu, X.; Yu, K.; Ornitz, D.M.; Long, F. Sequential roles of Hedgehog and Wnt signaling in osteoblast development. Development (Cambridge, England) 2005, 132, 49-60. [CrossRef]

29. Hill, T.P.; Spater, D.; Taketo, M.M.; Birchmeier, W.; Hartmann, C. Canonical Wnt/beta-catenin signaling prevents osteoblasts from differentiating into chondrocytes. Dev. Cell 2005, 8, 727-738. [CrossRef]

30. Maeno, T.; Moriishi, T.; Yoshida, C.A.; Komori, H.; Kanatani, N.; Izumi, S.; Takaoka, K.; Komori, T. Early onset of Runx2 expression caused craniosynostosis, ectopic bone formation, and limb defects. Bone 2011, 49, 673-682. [CrossRef] [PubMed]

31. Ornitz, D.M.; Xu, J.; Colvin, J.S.; McEwen, D.G.; MacArthur, C.A.; Coulier, F.; Gao, G.; Goldfarb, M. Receptor specificity of the fibroblast growth factor family. J. Biol. Chem. 1996, 271, 15292-15297. [CrossRef] [PubMed]

32. Pratap, J.; Galindo, M.; Zaidi, S.K.; Vradii, D.; Bhat, B.M.; Robinson, J.A.; Choi, J.-Y.; Komori, T.; Stein, J.L.; Lian, J.B. Cell growth regulatory role of Runx2 during proliferative expansion of preosteoblasts. Cancer Res. 2003, 63, 5357-5362. [PubMed] 
33. Galindo, M.; Pratap, J.; Young, D.W.; Hovhannisyan, H.; Im, H.J.; Choi, J.Y.; Lian, J.B.; Stein, J.L.; Stein, G.S.; van Wijnen, A.J. The bone-specific expression of Runx2 oscillates during the cell cycle to support a G1-related antiproliferative function in osteoblasts. J. Biol. Chem. 2005, 280, 20274-20285. [CrossRef]

34. Ghali, O.; Chauveau, C.; Hardouin, P.; Broux, O.; Devedjian, J.C. TNF- $\alpha$ 's effects on proliferation and apoptosis in human mesenchymal stem cells depend on RUNX2 expression. J. Bone Miner. Res. 2010, 25, 1616-1626. [CrossRef] [PubMed]

35. Lucero, C.M.; Vega, O.A.; Osorio, M.M.; Tapia, J.C.; Antonelli, M.; Stein, G.S.; Van Wijnen, A.J.; Galindo, M.A. The cancer-related transcription factor Runx2 modulates cell proliferation in human osteosarcoma cell lines. J. Cell. Physiol. 2013, 228, 714-723. [CrossRef]

36. Thomas, D.M.; Johnson, S.A.; Sims, N.A.; Trivett, M.K.; Slavin, J.L.; Rubin, B.P.; Waring, P.; McArthur, G.A.; Walkley, C.R.; Holloway, A.J. Terminal osteoblast differentiation, mediated by Runx2 and p27KIP1, is disrupted in osteosarcoma. J. Cell Biol. 2004, 167, 925-934. [CrossRef] [PubMed]

37. Zaidi, S.K.; Pande, S.; Pratap, J.; Gaur, T.; Grigoriu, S.; Ali, S.A.; Stein, J.L.; Lian, J.B.; Van Wijnen, A.J.; Stein, G.S. Runx2 deficiency and defective subnuclear targeting bypass senescence to promote immortalization and tumorigenic potential. Proc. Natl. Acad. Sci. USA 2007, 104, 19861-19866. [CrossRef] [PubMed]

38. Xiao, G.; Jiang, D.; Gopalakrishnan, R.; Franceschi, R.T. Fibroblast growth factor 2 induction of the osteocalcin gene requires MAPK activity and phosphorylation of the osteoblast transcription factor, Cbfa1/Runx2. J. Biol. Chem. 2002, 277, 36181-36187. [CrossRef]

39. Kim, H.J.; Kim, J.H.; Bae, S.C.; Choi, J.Y.; Kim, H.J.; Ryoo, H.M. The protein kinase C pathway plays a central role in the fibroblast growth factor-stimulated expression and transactivation activity of Runx2. J. Biol. Chem. 2003, 278, 319-326. [CrossRef]

40. Park, O.J.; Kim, H.J.; Woo, K.M.; Baek, J.H.; Ryoo, H.M. FGF2-activated ERK mitogen-activated protein kinase enhances Runx2 acetylation and stabilization. J. Biol. Chem. 2010, 285, 3568-3574. [CrossRef]

41. Ge, C.; Xiao, G.; Jiang, D.; Yang, Q.; Hatch, N.E.; Roca, H.; Franceschi, R.T. Identification and functional characterization of ERK/MAPK phosphorylation sites in the Runx2 transcription factor. J. Biol. Chem. 2009, 284, 32533-32543. [CrossRef] [PubMed]

42. Mundlos, S.; Otto, F.; Mundlos, C.; Mulliken, J.B.; Aylsworth, A.S.; Albright, S.; Lindhout, D.; Cole, W.G.; Henn, W.; Knoll, J.H.; et al. Mutations involving the transcription factor CBFA1 cause cleidocranial dysplasia. Cell 1997, 89, 773-779. [CrossRef]

43. Lee, B.; Thirunavukkarasu, K.; Zhou, L.; Pastore, L.; Baldini, A.; Hecht, J.; Geoffroy, V.; Ducy, P.; Karsenty, G. Missense mutations abolishing DNA binding of the osteoblast-specific transcription factor OSF2/CBFA1 in cleidocranial dysplasia. Nat. Genet. 1997, 16, 307-310. [CrossRef]

44. Bradley, J.P.; Levine, J.P.; Roth, D.A.; McCarthy, J.G.; Longaker, M.T. Studies in cranial suture biology: IV. Temporal sequence of posterior frontal cranial suture fusion in the mouse. Plast. Reconstr. Surg. 1996, 98, 1039-1045. [CrossRef]

45. Sahar, D.E.; Longaker, M.T.; Quarto, N. Sox9 neural crest determinant gene controls patterning and closure of the posterior frontal cranial suture. Dev. Biol. 2005, 280, 344-361. [CrossRef]

46. Behr, B.; Longaker, M.T.; Quarto, N. Differential activation of canonical Wnt signaling determines cranial sutures fate: a novel mechanism for sagittal suture craniosynostosis. Dev. Biol. 2010, 344, 922-940. [CrossRef]

47. Mikasa, M.; Rokutanda, S.; Komori, H.; Ito, K.; Tsang, Y.S.; Date, Y.; Yoshida, C.A.; Komori, T. Regulation of Tcf7 by Runx2 in chondrocyte maturation and proliferation. J. Bone Miner. Metab. 2011, 29, $291-299$. [CrossRef]

48. Gaur, T.; Lengner, C.J.; Hovhannisyan, H.; Bhat, R.A.; Bodine, P.V.; Komm, B.S.; Javed, A.; van Wijnen, A.J.; Stein, J.L.; Stein, G.S.; et al. Canonical WNT signaling promotes osteogenesis by directly stimulating Runx2 gene expression. J. Biol. Chem. 2005, 280, 33132-33140. [CrossRef]

49. Lee, M.H.; Kim, Y.J.; Yoon, W.J.; Kim, J.I.; Kim, B.G.; Hwang, Y.S.; Wozney, J.M.; Chi, X.Z.; Bae, S.C.; Choi, K.Y.; et al. Dlx5 specifically regulates Runx2 type II expression by binding to homeodomain-response elements in the Runx2 distal promoter. J. Biol. Chem. 2005, 280, 35579-35587. [CrossRef]

50. Selvamurugan, N.; Pulumati, M.R.; Tyson, D.R.; Partridge, N.C. Parathyroid hormone regulation of the rat collagenase-3 promoter by protein kinase A-dependent transactivation of core binding factor alpha1. J. Biol. Chem. 2000, 275, 5037-5042. [CrossRef] [PubMed] 
51. Krishnan, V.; Moore, T.L.; Ma, Y.L.; Helvering, L.M.; Frolik, C.A.; Valasek, K.M.; Ducy, P.; Geiser, A.G. Parathyroid hormone bone anabolic action requires Cbfa1/Runx2-dependent signaling. Mol. Endocrinol. 2003, 17, 423-435. [CrossRef] [PubMed]

52. Merciris, D.; Marty, C.; Collet, C.; de Vernejoul, M.C.; Geoffroy, V. Overexpression of the transcriptional factor Runx2 in osteoblasts abolishes the anabolic effect of parathyroid hormone in vivo. Am. J. Pathol. 2007, 170, 1676-1685. [CrossRef] [PubMed]

53. Aubin, J.; Triffitt, J. Mesenchymal Stem Ells and Osteoblast Differentiation; Bilezikian, J.P., Raisz, L.G., Rodan, G.A., Eds.; Academic Press: Cambridge, MA, USA, 2002.

54. Toyosawa, S.; Shintani, S.; Fujiwara, T.; Ooshima, T.; Sato, A.; Ijuhin, N.; Komori, T. Dentin matrix protein 1 is predominantly expressed in chicken and rat osteocytes but not in osteoblasts. J. Bone Miner. Res. 2001, 16, 2017-2026. [CrossRef] [PubMed]

55. Winkler, D.G.; Sutherland, M.K.; Geoghegan, J.C.; Yu, C.; Hayes, T.; Skonier, J.E.; Shpektor, D.; Jonas, M.; Kovacevich, B.R.; Staehling-Hampton, K.; et al. Osteocyte control of bone formation via sclerostin, a novel BMP antagonist. EMBO J. 2003, 22, 6267-6276. [CrossRef] [PubMed]

56. van Bezooijen, R.L.; Roelen, B.A.; Visser, A.; van der Wee-Pals, L.; de Wilt, E.; Karperien, M.; Hamersma, H.; Papapoulos, S.E.; ten Dijke, P.; Lowik, C.W. Sclerostin is an osteocyte-expressed negative regulator of bone formation, but not a classical BMP antagonist. J. Exp. Med. 2004, 199, 805-814. [CrossRef] [PubMed]

57. Xiao, Z.; Awad, H.A.; Liu, S.; Mahlios, J.; Zhang, S.; Guilak, F.; Mayo, M.S.; Quarles, L.D. Selective Runx2-II deficiency leads to low-turnover osteopenia in adult mice. Dev. Biol. 2005, 283, 345-356. [CrossRef]

58. Ducy, P.; Zhang, R.; Geoffroy, V.; Ridall, A.L.; Karsenty, G. Osf2/Cbfa1: a transcriptional activator of osteoblast differentiation. Cell 1997, 89, 747-754. [CrossRef]

59. Sato, M.; Morii, E.; Komori, T.; Kawahata, H.; Sugimoto, M.; Terai, K.; Shimizu, H.; Yasui, T.; Ogihara, H.; Yasui, N.; et al. Transcriptional regulation of osteopontin gene in vivo by PEBP2alphaA/CBFA1 and ETS1 in the skeletal tissues. Oncogene 1998, 17, 1517-1525. [CrossRef]

60. Harada, H.; Tagashira, S.; Fujiwara, M.; Ogawa, S.; Katsumata, T.; Yamaguchi, A.; Komori, T.; Nakatsuka, M. Cbfa1 isoforms exert functional differences in osteoblast differentiation. J. Biol. Chem. 1999, 274, 6972-6978. [CrossRef]

61. Lee, K.S.; Kim, H.J.; Li, Q.L.; Chi, X.Z.; Ueta, C.; Komori, T.; Wozney, J.M.; Kim, E.G.; Choi, J.Y.; Ryoo, H.M.; et al. Runx2 is a common target of transforming growth factor beta1 and bone morphogenetic protein 2, and cooperation between Runx2 and Smad5 induces osteoblast-specific gene expression in the pluripotent mesenchymal precursor cell line C2C12. Mol. Cell Biol. 2000, 20, 8783-8792. [CrossRef]

62. Banerjee, C.; McCabe, L.R.; Choi, J.Y.; Hiebert, S.W.; Stein, J.L.; Stein, G.S.; Lian, J.B. Runt homology domain proteins in osteoblast differentiation: AML3/CBFA1 is a major component of a bone-specific complex. J. Cell Biochem. 1997, 66, 1-8. [CrossRef]

63. Kern, B.; Shen, J.; Starbuck, M.; Karsenty, G. Cbfa1 contributes to the osteoblast-specific expression of type I collagen genes. J. Biol. Chem. 2001, 276, 7101-7107. [CrossRef] [PubMed]

64. Jimenez, M.J.; Balbin, M.; Lopez, J.M.; Alvarez, J.; Komori, T.; Lopez-Otin, C. Collagenase 3 is a target of Cbfa1, a transcription factor of the runt gene family involved in bone formation. Mol. Cell Biol. 1999, 19, 4431-4442. [CrossRef]

65. Rossert, J.; Eberspaecher, H.; de Crombrugghe, B. Separate cis-acting DNA elements of the mouse pro-alpha 1(I) collagen promoter direct expression of reporter genes to different type I collagen-producing cells in transgenic mice. J. Cell Biol. 1995, 129, 1421-1432. [CrossRef] [PubMed]

66. Bou-Gharios, G.; Garrett, L.A.; Rossert, J.; Niederreither, K.; Eberspaecher, H.; Smith, C.; Black, C.; Crombrugghe, B. A potent far-upstream enhancer in the mouse pro alpha 2(I) collagen gene regulates expression of reporter genes in transgenic mice. J. Cell Biol. 1996, 134, 1333-1344. [CrossRef]

67. Ivkosic, A.; Kronenberg, M.S.; Lichtler, A.C.; Kream, B.E. Analysis of internal deletions of a rat Col1a1 promoter fragment in transfected ROS17/2.8 cells. Coll. Antropol. 2006, 30, 401-404.

68. Takarada, T.; Hinoi, E.; Nakazato, R.; Ochi, H.; Xu, C.; Tsuchikane, A.; Takeda, S.; Karsenty, G.; Abe, T.; Kiyonari, H.; et al. An analysis of skeletal development in osteoblast-specific and chondrocyte-specific runt-related transcription factor-2 (Runx2) knockout mice. J. Bone Miner. Res. 2013, 28, 2064-2069. [CrossRef]

69. Adhami, M.D.; Rashid, H.; Chen, H.; Javed, A. Runx2 activity in committed osteoblasts is not essential for embryonic skeletogenesis. Connect. Tissue Res. 2014, 55, 102-106. [CrossRef] 
70. Bauer, O.; Sharir, A.; Kimura, A.; Hantisteanu, S.; Takeda, S.; Groner, Y. Loss of osteoblast Runx3 produces severe congenital osteopenia. Mol. Cell Biol. 2015, 35, 1097-1109. [CrossRef]

71. Wei, J.; Shimazu, J.; Makinistoglu, M.P.; Maurizi, A.; Kajimura, D.; Zong, H.; Takarada, T.; Lezaki, T.; Pessin, J.E.; Hinoi, E.; et al. Glucose uptake and Runx2 synergize to orchestrate osteoblast differentiation and bone formation. Cell 2015, 161, 1576-1591. [CrossRef] [PubMed]

72. Koga, T.; Matsui, Y.; Asagiri, M.; Kodama, T.; de Crombrugghe, B.; Nakashima, K.; Takayanagi, H. NFAT and Osterix cooperatively regulate bone formation. Nat. Med. 2005, 11, 880-885. [CrossRef] [PubMed]

73. Ortuno, M.J.; Susperregui, A.R.; Artigas, N.; Rosa, J.L.; Ventura, F. Osterix induces Col1a1 gene expression through binding to Sp1 sites in the bone enhancer and proximal promoter regions. Bone 2013, 52, 548-556. [CrossRef]

74. Artigas, N.; Urena, C.; Rodriguez-Carballo, E.; Rosa, J.L.; Ventura, F. Mitogen-activated protein kinase (MAPK)-regulated interactions between Osterix and Runx2 are critical for the transcriptional osteogenic program. J. Biol. Chem. 2014, 289, 27105-27117. [CrossRef]

75. Baek, W.Y.; Lee, M.A.; Jung, J.W.; Kim, S.Y.; Akiyama, H.; de Crombrugghe, B.; Kim, J.E. Positive regulation of adult bone formation by osteoblast-specific transcription factor osterix. J. Bone Miner. Res. 2009, 24, 1055-1065. [CrossRef]

76. Baek, W.Y.; de Crombrugghe, B.; Kim, J.E. Postnatally induced inactivation of Osterix in osteoblasts results in the reduction of bone formation and maintenance. Bone 2010, 46, 920-928. [CrossRef]

(C) 2019 by the author. Licensee MDPI, Basel, Switzerland. This article is an open access article distributed under the terms and conditions of the Creative Commons Attribution (CC BY) license (http:/ / creativecommons.org/licenses/by/4.0/). 